\title{
Substantiation and Selection of Optimal Method of Angren Section Field Drainage
}

\author{
Bakhtiyor Z. Baimirzaev ${ }^{1}$, Sokhibjon T. Matkarimov ${ }^{1 *}$ \\ ${ }^{1}$ Tashkent State Technical University named after Islam Karimov, Tashkent, Uzbekistan
}

\begin{abstract}
This article describes the results of the timely drainage of the Angren section using the horizontal drains method. It thereby creates favorable conditions for the effective operation of all technological links of the unit, protecting water resources of the area where the section is located using drainage and quarry waters in the national economy.
\end{abstract}

\section{Introduction}

During the exploitation of the Angren coal mine, surface and groundwater played an important role in the efficiency of the extraction and transport processes carried out up to a high moisture content of the rock mass and mineral. This causes negative geomechanical phenomena in the form of deformation, landslides, collapse, etc. Cutting sides and dumps, thereby hindering or impeding mining and transport equipment, noticeably reduces technological complexes' productivity, complicates and increases the cost of transportation of mineral and barren rocks.

Currently, water inflows coming within the Angren section are pumped to the surface from the North and South catchments by drainage plants. According to the monitoring carried out on the watersheds of the North and South drainage stations, the water flow in the section is between 500 and $1500 \mathrm{~m}^{3} / \mathrm{h}$, and during flood periods the flow can reach $3200 \mathrm{~m}^{3} / \mathrm{h}$. Timely drainage of the Angren section allows preventing those mentioned above negative geomechanical phenomena, thereby creating favorable conditions for the effective operation of all technological links of the unit and protecting the section area's water resources using drainage and quarry waters in the national economy [1].

\section{Experimental}

In this regard, measures to protect the section from water should include the following tasks:

- Protection against surface water by intercepting prone runoff;

- Protection from groundwater using drainage and barrage facilities to reduce the groundwater level in advance to the permissible value;
- Control of runoff and pumping of quarry water generated from static reserves; the dynamic influx of groundwater and precipitation;

- Cleaning from water outside the limits of the section.

The Angren coal mine is located in the upland area. As a result, the primary sources of water flooding of the section are atmospheric precipitation. They form surface water runoff. This is especially frequent during showers and intense snowmelt, erode slopes, flood mining horizons with sandy clay material. In this regard, based on practicality and economy, it is proposed to protect the Angren section from atmospheric precipitation by building water-protective dams and ditches. It is necessary to make a permanent dam outside the section's design boundary, which will ensure the removal of atmospheric precipitation abroad of the quarter regularly for the unit's entire life.

Protection against atmospheric rain falling directly within the section's quarry field is carried out by temporarily operating ditches erected along the opening ledge's contour and advanced as the opening face moves.

As a result of the analysis of hydrogeological, physical, and mechanical properties of rocks of the Angren coal mine, the surface method of drainage is the most effective for this deposit due to the drainage system and scheme's choice. According to specific techniques, the drainage system is the procedure for carrying out drainage measures associated with mining in space and time. There is an advanced, parallel, and combined drainage system. The latter (Figure 1) is the most common system used in deposits characterized by complex and challenging hydrogeological conditions similar to the Angren brown-coal deposit.

\footnotetext{
* Corresponding author: sohibtm@gmail.com
} 


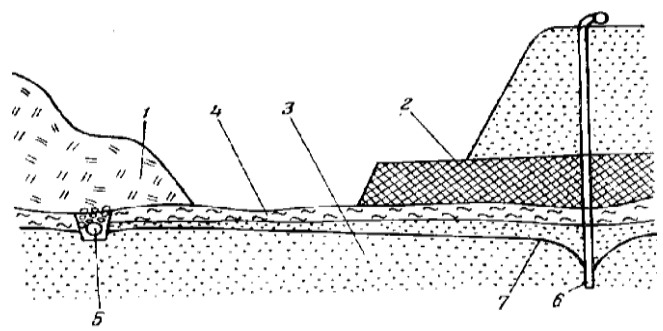

Fig. 1. Internal dumps drainage scheme, where: 1-drainage lines, carried out to drain the quarry field; 2 dehumidifiers; 3 collectors; 4-directions of water flow; 5-isohypses of coal bed soil; 6-axis of the split trench.

The main features of combined drainage are the sequential application of depression funnels with advanced drainage of mining operations during construction and parallel drainage simultaneously with their performance. For the conditions of the Angren coal mine, the most optimal is well and needle filtration methods. Drainage is the process of removing groundwater from a watered (aquifer) formation, as a result of which a water level decrease occurs in a specific area of water collection. Modern technical means of water reduction and methods of drainage are very diverse. The method with horizontal drains is the closest to the proposed method (Figure 2). The technique consists of laying a horizontal drill, which creates an outflow and reduces head forces' flow. We have developed a new method of drainage for watered formation, prone to deformations of the contour massif. Its essence lies in the contour massif before forming or before the critical development of noticeable deformations is drained. Simultaneously, the lower part of the slope is partially unloaded in the area of its lower edge.
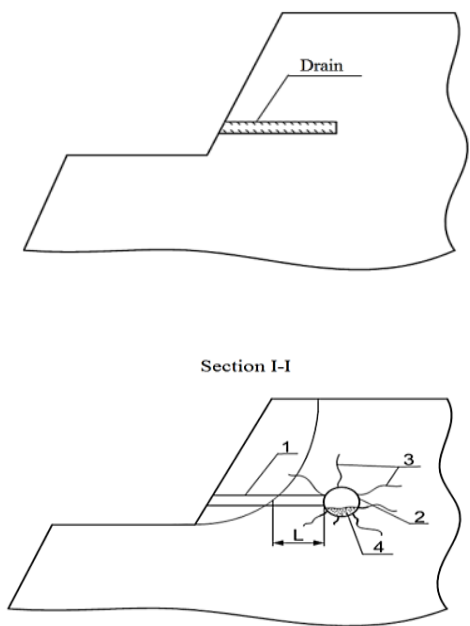

Fig. 2. Draining of the filter along with the entire slope height with frequent horizontal transverse drains.

Several wells are drilled at an altitude of $0.5-1 \mathrm{~m}$, with a $50-150 \mathrm{~mm}$ diameter at a not large-angle towards the developed space.

The wells' diameter is selected depending on the available equipment and the amount of water inflow (Figure 3).

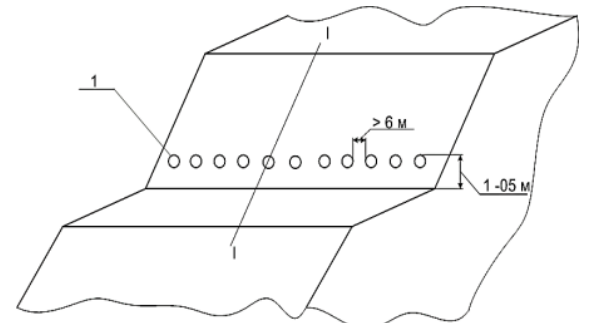

Fig. 3. Proposed method of a pit side drainage. Legend: 1 shows a well with a plastic pipe installed; 2 - camouflage cavity; 3 - cracks; 4 - concrete.

$\mathrm{L}$ is the distance from the movement plane to the camouflage cavity. After the drilling tool is removed from the well, an explosive charge is introduced into it. The amount of explosive charge depends on the physical and mechanical properties of the rocks. Its amount should be sufficient to form not a large camouflet cavity, but at the same time, have a minimum seismic effect on the array. The weight of the charge depends on the required volume of the camouflage cavity is calculated by the following formula [2]:

$$
Q=\frac{V}{P_{P}}
$$

where $\mathrm{Q}$ is the charge weight of the internal explosion in $\mathrm{kg}$;

$\mathrm{V}$ - Cavity volume obtained after an internal explosion in $\mathrm{dm}^{3}$.

$\mathrm{PP}$ - is a shooting index whose values for clay rocks range from 100 to $1400 \mathrm{dm}^{3} / \mathrm{kg}$.

M.A. Sadovsky proposed a formula for calculating the safe distance of impact of an explosive seismic wave:

$$
R_{c}=k_{c} \cdot d \cdot \sqrt[3]{Q}
$$

where $\mathrm{Rc}$ is the distance from the explosion site in $\mathrm{m}$; $\mathrm{Kc}$ - coefficient, the value of which depends on soil properties in the base of protected structures; the numerical values of this coefficient for various soils range from 3 to 20 , in particular for clay soils, it is 9 ; d - Explosion action factor, in case of camouflage explosion equal to 1.2 ;

$\mathrm{Q}$ - Explosive charge value in $\mathrm{kg}$.

The distance from the camouflage cavity to the plane of movement of rocks shall be within the following limits:

$$
R_{c} \geq L
$$

where: $\mathrm{L}$ is the distance from the camouflage cavity to the plane of movement of rocks. The distance between the wells shall not exceed $8 \mathrm{~m}$. After the good booms, a camouflage cavity forms in the massif. Under an explosion around it, existing cracks are opened, and new ones are created due to rocks' micro fracturing. This contributes to an increase in water flow into the cavity. Then the plastic pipe is installed in the well. At its length, the upper part of the tube, from the camouflet cavity, is perforated with holes that will allow filtering water not captured by the camouflet cavity. After that, a rapidly hardening solution is supplied through the pipe to the formed camouflage cavity to create the bottom of 
the water intake, which reduces water leakage to the lower horizons (Figure 3).

Drainage grooves pass along the slope to drain water to the buzzer, preventing its drainage to the lower horizons. The distance between the wells is less than $8 \mathrm{~m}$ because the new exposure planes created by the wells unload the contour massif. As is known in the lower edge of the slopes of the ledges and sides, stress concentration zones are formed, which are one of the reasons for the development of deformations. Stress distributions, according to the method of photomechanics, were investigated. Numerous works are devoted to the technique of photomechanics in solving mountain problems [3]. In these works, the procedure for conducting experiments is given in detail. While studying this method, various degrees of drainage of the sides of the quarry were modeled. In particular, Figure 4a shows a picture of the strips obtained on the drilling equipment installation on models made of optically active material.

As you can see in stress symbols, in untouched slope models, the change of maximum tangent stresses occurs smoothly. According to section 1-1 (Figure 4b), stress curves in the massif are built. On the circuit, these stresses take values of 0.6 in the strip's order, then at a distance of about 1/3.6 of the ledge's height, they reach minimum values, then gradually increase in values in an entire array.

The stress concentration creates conditions for forming the plane of rocks in the massif along the sloping plane. When the plane of exposure is initiated, outside the plane of movement of stones, stresses are redistributed in the contour massif. Their concentration on the newly formed plane of direction is redistributed. Stress redistribution leads to the formation of a new rock displacement plane located in the massif's depth.

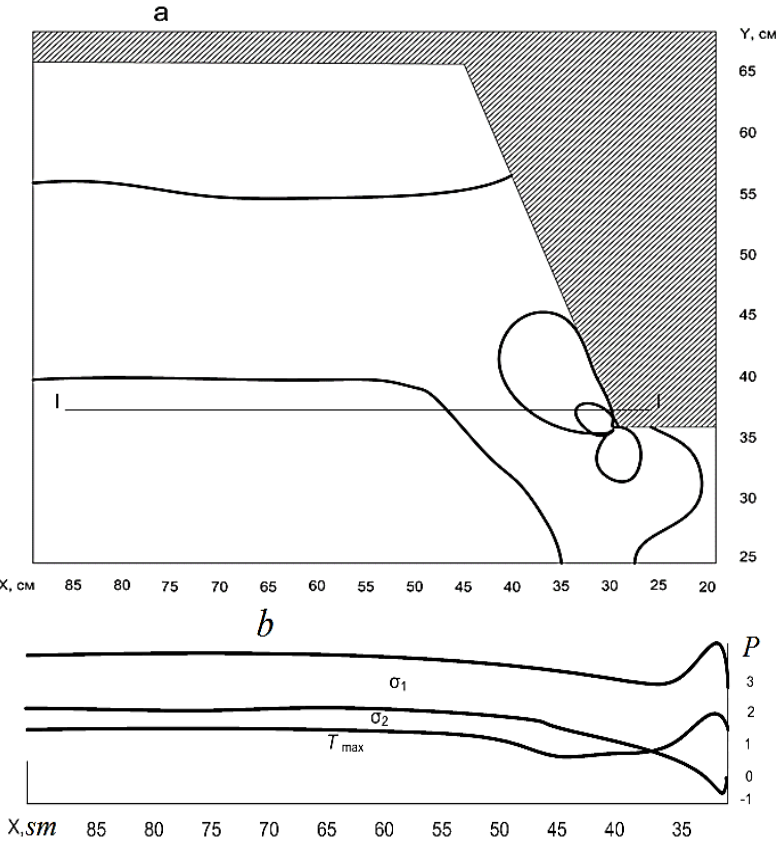

Fig. 4. The pattern of stripes with intact contour massif (a) and stress pure (b)
Figure 5a shows a picture of the strips obtained on a slope model with a camouflage cavity. From the stress endures (Figure 5b), it is clear that the voltage surges occur at a certain distance from the slope. At the intersection of the well with the voltage slope, values of about 0.3 of the order of the strip, then the stress values decrease in the camouflage cavity, here the stress value increases sharply to 0.5 of the order of the strip, after which it declines to 0.37 , then gradually increases in values in an untouched mass [4].

Thus, in the slope massif at the distance of the camouflet cavity, an area of stress concentration is formed that creates conditions for the emergence of a new plane of movement of rocks inside rocks. Due to the increase in holding forces, stones acquire a stable state. Increasing the distance between wells more than $8 \mathrm{~m}$ leads to the fact that the necessary stress redistribution to unload the existing rock movement plane does not occur. The danger of landslide formation remains.

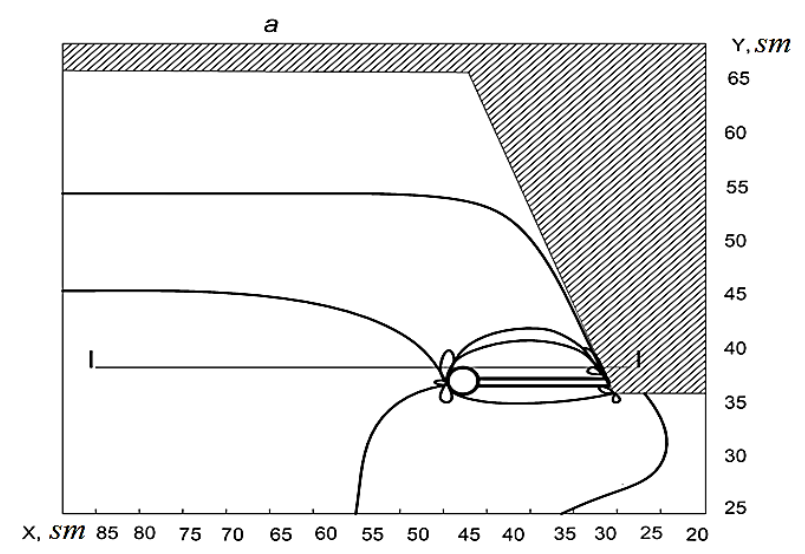

Section I-I

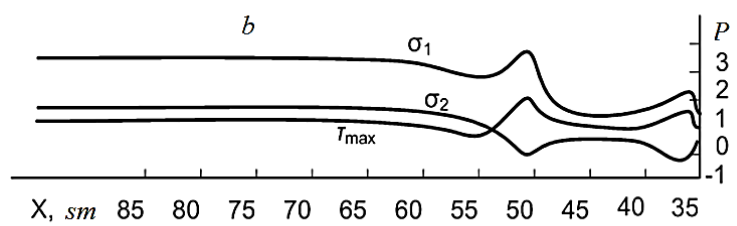

Fig. 5. Strip pattern in camouflage cavity in massif (a) and stress pure (b).

The proposed method of drainage of slope rocks allows: 1) to drain the contour massif; 2) due to redistribution of stresses in the massif, unload the lower part of the slope, increasing its stability.

Laboratory-experimental studies were carried out using low-module optically sensitive models using the photomechanical method. Simultaneously, the peculiarity of the experiments conducted differed from the previous ones. We attempted to use horizontal models to qualitatively determine the depth stresses in the massif around (different configurations) quarry contours.

These studies try to supplement the data on the stressed - deformed state of the instrument array, which was 
previously obtained based on vertical models' reviews. In the beginning, according to the method developed in VNIMI, the planes of movement of rocks in the massif are built according to the sections intended for drainage of the pit side section. Then the location of the camouflage cavity and length of good drilling are determined by formulae 2 and 3. Formula 1 is used to calculate explosive charge to form a camouflage cavity of the required volume. On the lower edge of the slope, wells of the required length are drilled at an angle of $5^{\circ}$. Design charge of explosive is established in the obtained wells, and boreholes are performed at intervals of 70$100 \mathrm{~ms}$.

To prevent the possibility of showering and pouring wells, a plastic pipe is installed in them, the length of which is equal to the size of the well from the mouth to the beginning of the camouflage cavity. Cement solution is fed through the pipe into a camouflet cavity at the rate of $1 / 4$ of camouflet cavity volume. A drainage ditch runs along the slope to the nearest buzzer.

Concerning the method of photomechanics, there are numerous works in solving mountain problems. In these works, the procedure for conducting experiments is given in detail. Using the data, various methods for draining the sides of the quarry were modeled. First, a map of the Angren section's zoning is built based on the location of water flows and the contour of the slopes of the sides. Based on the results obtained, the most dangerous areas are determined from the point of view of stability and watering. After that, measures for their drainage are selected.

The most watered is the north side of the Angren section. It poses a significant threat to sustainability. Therefore, it is essential to develop an action to drain this board. We propose to apply combined measures to reduce water inflow in this area. At a distance of more than 60 $\mathrm{m}$, vertical wells are drilled from the upper edge of the side slope. Their depth is determined by the center of the location of the aquifer. Water pumping pumps are installed in the wells. Horizontal wells are drilled on lower aquifers, with a slope towards the developed space of about 10 .

Drilling depth is determined by calculation. To do this, you create a sliding plane of the section board pattern along this section's sections. On the aquifer, the lower edge of the ledge to the sliding plane is determined. The safe seismic distance from the impact of camouflage explosion on the array is calculated. The sum of these distances determines the depth of good drilling. The method of construction of horizontal gravity drainage wells as described above.

The water collected by wells according to the drain channels system is bypassed into the southern sump for subsequent pumping. Combined measures to reduce water inflow will completely drain this northbound side section, thereby increasing its stability.

\section{Results and discussion}

As a result of the long-standing time, the section's working side is also susceptible to landslide phenomena. The largest is the "Central" landslide.

One of the main factors affecting its stability is watering the massif of rocks that make up the board in the absence of atmospheric precipitation; the central water inflow is groundwater from the neighboring stream.

The surface waters of the stream intercept the drainage channel. Groundwater is to be withdrawn through pumps located in vertical wells.

However, due to the lack of pumps and their frequent failure, it does not work. According to this, we propose to replace vertical wells with pumps with horizontal gravity.

\section{Conclusion}

Horizontal wells are drilled from the constructed portal before crossing the aquifer. Camouflage explosion and installation of reinforcing plastic pipes, the wellhead is cemented. Thereafter, incoming water is passed through the water line to the drain channel.

Thus, the proposed method of draining the quarry field of the Angren section has the following advantages:

1. No pumps; 2 . There is no need to supply electricity;

3. No energy costs; 4 . There is no need for repair works; 5. No maintenance and security personnel.

\section{References}

1. I.K. Umarova, S.T. Matkarimov, \& D.B. Makhmarezhabov, Obogashchenie Rud, 2, 29-33 (2020)

2. M.A. Sadovsky, V.F. Pisarenko. Seismic process in the block environment. - Moscow: Science, 95 (1991)

3. A.M. Halperin. Geomechanics of open mining. - M: Publishing House of Moscow State University (2003)

4. I.M. Yaltanets. Design of open hydromechanical and other developments. - M: MGSU Publishing House, 752 (2003) 